\title{
Molecular phylogeny of Lathyrus species: insights from sequence-related amplified polymorphism markers
}

\author{
S. Marghali, A. Touati, M. Gharbi, D. Sdouga and N. Trifi-Farah \\ Laboratory of Molecular Genetics, Immunology and Biotechnology, \\ Faculty of Sciences of Tunis, University of Tunis El Manar-Campus Universitaire, \\ El Manar 2, Tunisia \\ Corresponding author: S. Marghali \\ E-mail: soniamarghali@yahoo.fr \\ Genet. Mol. Res. 15 (1): gmr.15017198 \\ Received August 14, 2015 \\ Accepted October 19, 2015 \\ Published March 31, 2016 \\ DOI http://dx.doi.org/10.4238/gmr.15017198
}

ABSTRACT. Sequence-related amplified polymorphism (SRAP) markers were used to evaluate the intra- and interspecific variation among 40 Lathyrus genotypes (four species) (Fabaceae). Ten SRAP primer combinations resulted in a total of 94 bands, and they exhibited high interspecific variability. The genetic differentiation among Lathyrus, estimated using AMOVA, was highly significant. The results indicated that $58 \%$ of the total genetic variation existed among species, and $42 \%$ of the differentiation was within species. This was explained by the high level of genome conservation of these species as well as the recent and slow evolution of this genus. These results were confirmed by the topology of the neighbor-joining cladogram and the results of the principal coordinate analysis. Our data support previous results based on seed protein diversity. These results make SRAP markers choice markers for the study of functional polymorphism that is directly related to the transcriptomic data. The SRAP markers used in this study provide an accurate picture of the population structure within Lathyrus germplasm, which is critically important information for the design of genetic diversity and structure analyses. 
Moreover, further extensive studies are necessary to fully examine other Lathyrus species and tests that adopt the SRAP technique to enrich the Lathyrus library for next-generation sequencing, thus providing a potent protocol for the study of polymorphism.

Key words: Lathyrus; Genetic variability; SRAP markers; Phylogeny

\section{INTRODUCTION}

Lathyrus is a large genus containing approximately 160 species (Lewis et al., 2005), which are mostly located in Europe, Asia, and North America, and species also extend to temperate South America and tropical East Africa. The genus' center of diversity is primarily in the Mediterranean and Irano-Turanian regions (Kupicha, 1981).

Lathyrus has been considered an important low-risk aversion crop, because it has relatively good tolerance to waterlogging (in the case of flooding). Because it requires low production costs, it has the ability to grow on residual moisture after the end of the rains or in case of drought (Wuletaw et al., 1997).

Several Lathyrus species are cultivated for human consumption, animal feed, fodder, and ornamental purposes (Sarker et al., 1997). The genus is a recommended crop for diverse types of farming systems, and there is potential for further exploitation of the Lathyrus gene pool. Therefore, the collection, conservation, characterization, study of genetic diversity, and utilization of Lathyrus deserve further attention as a priority research area. To prevent genetic erosion and extinction, Lathyrus conservation was given priority by Biodiversity International (former IBPGR and IPGRI) in 1985.

Unlike morphological descriptors, molecular markers detect diversity and differences among and within species directly at the DNA level and independent of environmental factors. Several PCRbased molecular detection methods have been developed, including amplified fragment length polymorphism (AFLP), random amplified polymorphic DNA (RAPD), simple sequence repeat (SSR), inter-simple sequence repeat (ISSR), and sequence-related amplification polymorphism (SRAP). All of these molecular markers are commonly used in genomic analysis (Jones et al., 2009), and most have been used in Lathyrus populations for relationship estimation, ecotype identification, determination of population structure (Belaïd et al., 2006; Ghorbel et al., 2014), and construction of genetic linkage maps (Chowdhury and Slinkard, 2000; Skiba et al., 2004).

The SRAP technique was developed by Li and Quiros (2001) to simplify the AFLP detection procedure, increase throughput, and improve reproducibility compared to RAPD. The simple detection procedure was produced by skipping the restriction enzyme digestion and ligation of target DNA fragments and adapters in the AFLP detection protocol. The sizes of SRAP primers are similar to those used in AFLP, but the protocol includes a single-PCR round instead of two. Compared to RAPD, SRAP uses a pair of primers with 16 to 22 nucleotides instead of 10-mer short primers. Therefore, one SRAP primer can combine with an unlimited number of other primers, which gives SRAP a big advantage over RAPD.

It is worth noting that there is a difference in the GC content between gene coding sequences and other sequences in the plant genome. Based on this difference, Li and Quiros (2001) designed two sets of SRAP primers: 1) the forward primers contained a GGCC cassette near the 3'-end of the primer that might preferentially anneal to the GC-rich regions; 2) the reverse primer set contained an AATT cassette that would preferentially anneal SRAP primers to introns and gene spacers, so that SRAP markers could preferentially amplify gene-rich genomic regions. 
The SRAP technique was used for several purposes, including genetic map construction (Li et al., 2003; Gao et al., 2007; Sun et al., 2007), QTL mapping (Chen et al., 2007; Fu et al., 2007; Zhang et al., 2009b), gene tagging and cloning (Rahman et al., 2007; Yi et al., 2008; Zhang et al., 2009a), and genetic diversity (Riaz et al., 2001; Budak et al., 2004a,b; Vandemark et al., 2006).

In the present study, SRAP markers were exploited to explain the genetic diversity and variation within and among four Lathyrus species and to estimate their relationships.

\section{MATERIAL AND METHODS}

\section{Plant materials and DNA extraction}

Ten individuals from four Lathyrus species (L. sativus, L. ochrus, L. sylvestris, and L. cicera) were randomly selected (Table 1). Genomic DNA was extracted from young leaves using a Pure Link-Total Plant DNA Purification Kit (Invitrogen, France) according to the manufacturer protocol. DNA concentrations were measured with a Nanodrop ND 100 spectrophotometer (Nanodrop Technologies Inc., Wilmington, DE, USA) to assure DNA amplifications with good profiles.

Table 1. Description of Lathyrus species.
\begin{tabular}{l|l|l|l|l|l}
\hline Species & Geographical origin & Locality & Form & Biological type & Designation \\
\hline L. cicera & \multirow{2}{*}{ Tunisia } & Zarsis & Cultivated & Annual & LLLCZ \\
\cline { 3 - 6 } & B. ochrus & Seja & Spontaneous & Perennial & LObe \\
\cline { 3 - 6 } L. sativus & Sfax & Cultivated & Annual & SF \\
\hline L. sylvestris & Hungary & Kompolt & Spontaneous & Perennial & SH \\
\hline
\end{tabular}

\section{SRAP analysis}

The SRAP primer combinations were randomly selected, and primer sequences are shown in Table 2.

Table 2. Name and sequence of the SRAP primers used for Lathyrus genotype screening.

\begin{tabular}{l|l|l|l}
\hline \multicolumn{2}{l|}{ Forward primers } & \multicolumn{2}{l}{ Reverse primers } \\
\hline F8 & 5'-GTA GCA CAA GCC GGA AT-3' & R7 & 5'-GAC ACC GTA CGA ATT TGC-3' \\
\hline F9 & 5'-GTA GCA CAA GCC GGA CC-3' & R8 & 5'-GAC ACC GTA CGA ATT GAC-3' \\
\hline F13 & 5'-CGA ATC TTA GCC GGC AC-3' & R9 & 5'-GAC ACC GTA CGA ATT TGA-3' \\
\hline F14 & 5'-TGA GTC CAA ACC GGA GC-3' & R15 & 5'-CGC ACG TCC GTA ATT CCA-3' \\
\hline
\end{tabular}

All PCR amplifications were performed in a $25-\mu \mathrm{L}$ reaction volume containing: $1 \mu \mathrm{L}$ primers (0.5 $\mathrm{LL} \mathrm{Me} \mathrm{+} \mathrm{0.5} \mathrm{\mu L} \mathrm{Em),} 30 \mathrm{ng}$ genomic DNA, $0.5 \mu \mathrm{L}$ Taq DNA polymerase (5 U), $1.5 \mu \mathrm{L}$ dNTPs (0.2 mM), $2.5 \mu \mathrm{L}$ 10X buffer $\left(\mathrm{Mg}^{2+}\right.$ free), $1.5 \mu \mathrm{L} \mathrm{MgCl}(50 \mathrm{mM})$, and $16 \mu \mathrm{L} \mathrm{ddH}_{2} \mathrm{O}$.

All PCRs were performed in a TProfessional TRIO thermocycler (Biometra, An Analytic Jena Company), and were subjected to the following program: initial denaturation at $94^{\circ} \mathrm{C}$ for 5 min, five cycles of three steps: 1 min denaturing at $94^{\circ} \mathrm{C}, 1 \mathrm{~min}$ annealing at $35^{\circ} \mathrm{C}$, and $1 \mathrm{~min}$ extension at $72^{\circ} \mathrm{C}$. In the subsequent 35 cycles: 1 min denaturing at $94^{\circ} \mathrm{C}, 1$ min annealing at $50^{\circ} \mathrm{C}$, and 1 min extension at $72^{\circ} \mathrm{C}$; a final 10 min extension at $72^{\circ} \mathrm{C}$.

PCR products were separated on $3 \%$ agarose gels, and electrophoretic patterns were visualized using a Gel-Doc 2000 image analysis system (Bio-Rad, USA). Clear and reproducible bands were then scored and used in subsequent analyses. 


\section{Data analysis}

SRAP markers are considered dominant, and therefore, we assumed that each band represented the phenotype at a single biallelic locus. Therefore, to generate a binary data matrix, only reproducible and consistent SRAP fragments were scored as present (1) or absent (0) for all of the samples.

In order to measure the informativeness of the marker, the polymorphism information content (PIC) was calculated for each primer combination (Table 3). PIC values were calculated using the following formula: PIC = $1-S_{i=1} f i^{2}$ (Smith et al., 1997), where $f i^{2}$ is the frequency of the $i$ th allele.

Table 3. Description of oligonucleotide primers used for SRAP analyses.

\begin{tabular}{l|c|c|c}
\hline Primer combination & PIC\% & Max. No. of bands & Band size range (bp) \\
\hline F8R7 & 95.00 & 9 & $600 / 2036$ \\
\hline F9R7 & 96.76 & 8 & $400 / 3000$ \\
\hline F9R9 & 98.26 & 9 & $450 / 2500$ \\
\hline F9R15 & 97.03 & 7 & $400 / 1600$ \\
\hline F13R9 & 96.36 & 8 & $506 / 3054$ \\
\hline F13R7 & 97.30 & 12 & $400 / 1700$ \\
\hline F13R15 & 98.05 & 8 & $150 / 1600$ \\
\hline F14R8 & 93.11 & 6 & $506 / 3200$ \\
\hline F14R15 & 96.95 & 7 & $150 / 2000$ \\
\hline
\end{tabular}

The estimation of genetic variation was conducted using the POPGENE software package version 3.2 for the calculation of the following parameters (Table 4): number of different alleles $\left(N_{\mathrm{A}}\right)$, number of effective alleles $\left(N_{E}\right)$, Shannon's information index $(I)$, expected heterozygosity $\left(H_{E}\right)$, and percentage of polymorphic loci (PPL).

Using the POPGENE software package (Yeh et al., 1999), Nei's analysis of gene diversity in subdivided populations was also performed to calculate and visualize heterozygosity at the pooled population level $\left(H_{\mathrm{T}}\right)$, heterozygosity at each population level $\left(H_{\mathrm{S}}\right)$, genetic diversity among populations $\left(G_{\mathrm{ST}}\right)$, and estimates of gene flow from $G_{\mathrm{ST}}\left(N_{\mathrm{m}}\right)$ (Table 5).

Table 4. Estimation of genetic variation in Lathyrus species using SRAP markers or diversity parameters of four Lathyrus species analyzed using SRAP markers.

\begin{tabular}{|c|c|c|c|c|c|c|c|c|}
\hline & & $\mathrm{N}$ & $N_{\mathrm{A}}$ & $N_{\mathrm{E}}$ & 1 & $H_{\mathrm{E}}$ & NPL & PPL \% \\
\hline \multirow[t]{2}{*}{ L. sativus Sfax } & Mean & \multirow[t]{2}{*}{10.000} & 1.5000 & 1.2856 & 0.1707 & 0.2584 & \multirow[t]{2}{*}{41} & \multirow[t]{2}{*}{$50.0 \%$} \\
\hline & SE & & 0.5031 & 0.3533 & 0.1922 & 0.2785 & & \\
\hline \multirow[t]{2}{*}{ L. ochrus Beja } & Mean & \multirow[t]{2}{*}{10.000} & 1.5366 & 1.3780 & 0.2107 & 0.3081 & \multirow[t]{2}{*}{44} & \multirow{2}{*}{$53.66 \%$} \\
\hline & SE & & 0.5017 & 0.4145 & 0.2161 & 0.3056 & & \\
\hline \multirow[t]{2}{*}{ L. sylvestris Hungary } & Mean & \multirow[t]{2}{*}{10.000} & 1.3902 & 1.2401 & 0.1402 & 0.2096 & \multirow[t]{2}{*}{32} & \multirow[t]{2}{*}{$39.02 \%$} \\
\hline & SE & & 0.4908 & 0.3532 & 0.1920 & 0.2778 & & \\
\hline \multirow[t]{2}{*}{ L. cicera Zarsis } & Mean & \multirow[t]{2}{*}{10.000} & 1.5854 & 1.3434 & 0.2044 & 0.3079 & \multirow[t]{2}{*}{48} & \multirow[t]{2}{*}{$58.54 \%$} \\
\hline & SE & & 0.4957 & 0.3623 & 0.1952 & 0.2809 & & \\
\hline \multirow[t]{2}{*}{ Species level } & Mean & \multirow[t]{2}{*}{40.000} & 2.0000 & 1.7286 & 0.4063 & 0.5906 & \multirow[t]{2}{*}{82} & \multirow[t]{2}{*}{$100.0 \%$} \\
\hline & SE & & 0.0000 & 0.2577 & 0.1044 & 0.1216 & & \\
\hline
\end{tabular}

$N_{\mathrm{A}}=$ observed number of alleles; $N_{\mathrm{E}}=$ effective number of alleles; $\mathrm{H}=$ Nei's (1973) gene diversity; I = Shannon's information index; NPL = number of polymorphic loci; $\mathrm{PPL}=$ percentage of polymorphic loci. 
Table 5. Nei's analysis of gene diversity in Lathyrus species.

\begin{tabular}{l|c|c|c|c|c}
\hline & $\mathrm{N}$ & $H_{\mathrm{T}}$ & $H_{\mathrm{s}}$ & GsT & $N_{\mathrm{m}}$ \\
\cline { 1 - 5 } Mean & \multirow{2}{*}{40} & 0.4063 & 0.1815 & 0.5533 & 0.4037 \\
\cline { 1 - 5 } SD & & 0.0109 & 0.0128 & - & - \\
\hline
\end{tabular}

$H_{\mathrm{T}}=$ heterozygosity at the pooled population level; $H_{\mathrm{S}}=$ heterozygosity at each population level; $G_{\mathrm{ST}}=$ genetic diversity among populations; $N_{\mathrm{m}}=$ estimate of gene flow from $G_{\mathrm{ST}}$.

For estimations of variance components among and within studied species, analyses of molecular variance (AMOVA) were performed using GenAIEx 6.5 (Peakall and Smouse, 2012).

\section{Clustering}

Dendrograms for individual samples were constructed according to the hierarchical neighbor joining $(\mathrm{NJ})$ method using the DARWIN 5.0.158 software program (Perrier and Jacquemoud-Collet, 2006).

Based on the results of the hierarchical cluster, a number of clusters $(k)$ was set to define the population structure by the k-means algorithm using the XLSTAT software version 2014/2013 (Addinsoft). The k-means classification was made based on the determinant (w) with 500 iterations and 0.00001 convergences (MacQueen, 1967). The program was run 50 times for each subpopulation (k), and values ranged from 2 to 9 with a random starting partition.

To infer population structure of studied Lathyrus species, the model-based clustering approach of the STRUCTURE 2.3.4 program was used. It is assumed that within populations, the loci are at Hardy-Weinberg equilibrium. The calculations were carried out under an admixture ancestry model, and the program was run 50 times for each subpopulation $(K)$ value (ranging from 2 to 9 ) with 50,000 replicates for burn-in and 50,000 replicates during the analysis.

The output of the hierarchical ascending classification results was a similarity matrix between pairs of individuals based on Jaccard's coefficient, and the output of the remaining classification results was a similarity matrix based on the Pearson coefficient.

\section{Multidimensional scaling}

Principal component analyses (PCA) and principal coordinate analyses (PCOA) were performed using XLSTAT to examine the genetic relationship among studied species (Gower, 1966).

The PCA output was a correlation matrix, while the PCoA output was a similarity matrix based on the Pearson coefficient.

\section{RESULTS}

Genetic similarity was observed among 40 samples belonging to four Lathyrus species ( $L$. sativus, L. ochrus, L. sylvestris, and L. cicera). Ten SRAP primer combinations, using four forward primers and four reverse primers, resulted in a total of 82 bands. None of the scored bands was monomorphic in all species. However, some of the bands were monomorphic within the same population, which characterized each target population. The number of observed bands ranged from six (F13-R8 primers) to 12 (F13-R7 primers), and the average per primer combination was 8.2. Primer utility was estimated using PIC indices. PIC values for primers ranged from $93.11 \%$ (F13-R8) to $98.26 \%$ (F9-R9) (Table 3). In this analysis, all of the PIC values were greater than 
0.9, which indicated that the observed polymorphism was significant (Xie et al., 2011). In fact, the average PIC values highlighted considerable genetic variation of Lathyrus germplasm, which should be considered as a background for future breeding programs.

\section{SRAP polymorphism}

Several parameters were calculated for each accession, including $N_{\mathrm{A}}, N_{\mathrm{E}}$, I, PPL, Nei's (1973) gene diversity $(H)$, and the number of polymorphic loci (Table 4).

$N_{\mathrm{A}}$ values ranged from 1.390 (L. sylvestris Hungary) to 1.585 (L. cicera Zarsis). $N_{\mathrm{E}}$ values (per locus) ranged from 1.24 (L. sylvestris Hungary) to 1.378 (L. ochrus Beja), and $N_{\mathrm{E}}=1.728$ at the species level.

PPL values ranged from 39.02 to $58.54 \%$ for 32 and 48 polymorphic loci observed in $L$. sylvestris and $L$. cicera, respectively. $H_{\mathrm{E}}$ values ranged from 0.2 (L. sylvestris) to 0.3 (L. ochrus).

The I value at the species level was 0.59 , and it showed the same bias as expected heterozygosis in that $L$. sylvestris and $L$. cicera exhibited the least $(0.14)$ and greatest $(0.12)$ diversity, respectively.

The genetic differentiation among Lathyrus estimated by AMOVA analysis was highly significant $(P<0.001$; Table 6$)$. Moreover, the results showed that $58 \%$ of the total genetic variation existed among species, and $42 \%$ of the differentiation was within species. This result can be explained by the high levels of genomic conservation observed in these species as well as the recent and slow evolution of this genus. On the other hand, the low rate of intraspecific variation could be due to the specificity of the primers used and the low mutation rates of the amplified ORFs. Genetic diversity is essential for the long-term survival of a species and its adaptability to the environment. Thus, it is important to be aware of the inter- and intraspecific diversity before developing any protection and management strategies for an endangered species (Hamrick and Godt, 1996).

Table 6. Analysis of molecular variance (AMOVA) for four Lathyrus species.

\begin{tabular}{l|c|c|c|c|c|c}
\hline Source & d.f. & SSD & MS & SD & $\%$ & P \\
\hline Among populations & 3 & 368.675 & 122.892 & 11.462 & $58 \%$ & 0.001 \\
\hline Within populations & 36 & 297.700 & 8.269 & 8.269 & $42 \%$ & 0.001 \\
\hline Total & 39 & 666.375 & & 19.732 & $100 \%$ & 0.001 \\
\hline
\end{tabular}

d.f. = degrees of freedom; SSD = sum of squared deviations; $M S=$ mean squared deviation; $P$ = probability of obtaining a more extreme component estimate by chance alone, estimated by computing 999 permutations.

\section{Clustering based on SRAP markers}

The NJ dendrogram (Figure 1), which represents relationships between individuals of different species, shows that the $L$. cicera genotypes formed one cluster with two sub-clusters (the first with six CZ genotypes and the second with four CZ genotypes). The $L$. sylvestris genotypes also formed a single cluster with two sub-clusters, which included the first with nine SH genotypes divided into two groups (SH7, SH6, SH8, SH9, and $\mathrm{SH} 10$ ) and (SH2, SH1, SH4, and SH3), and the second with the SH5 genotype. Genotypes from L. ochrus and L. sativus were grouped into one cluster with two sub-clusters. The first sub-cluster included OB genotypes that were divided into two groups (OB2, OB1, OB7, OB3, OB5, OB4, and OB6) and (OB10, OB9, and OB8), and the second included SS genotypes divided into two groups [(SS9, SS7, SS8, SS6, and SS10) and (SS4, SS3, SS5, SS2, and SS1)]. 

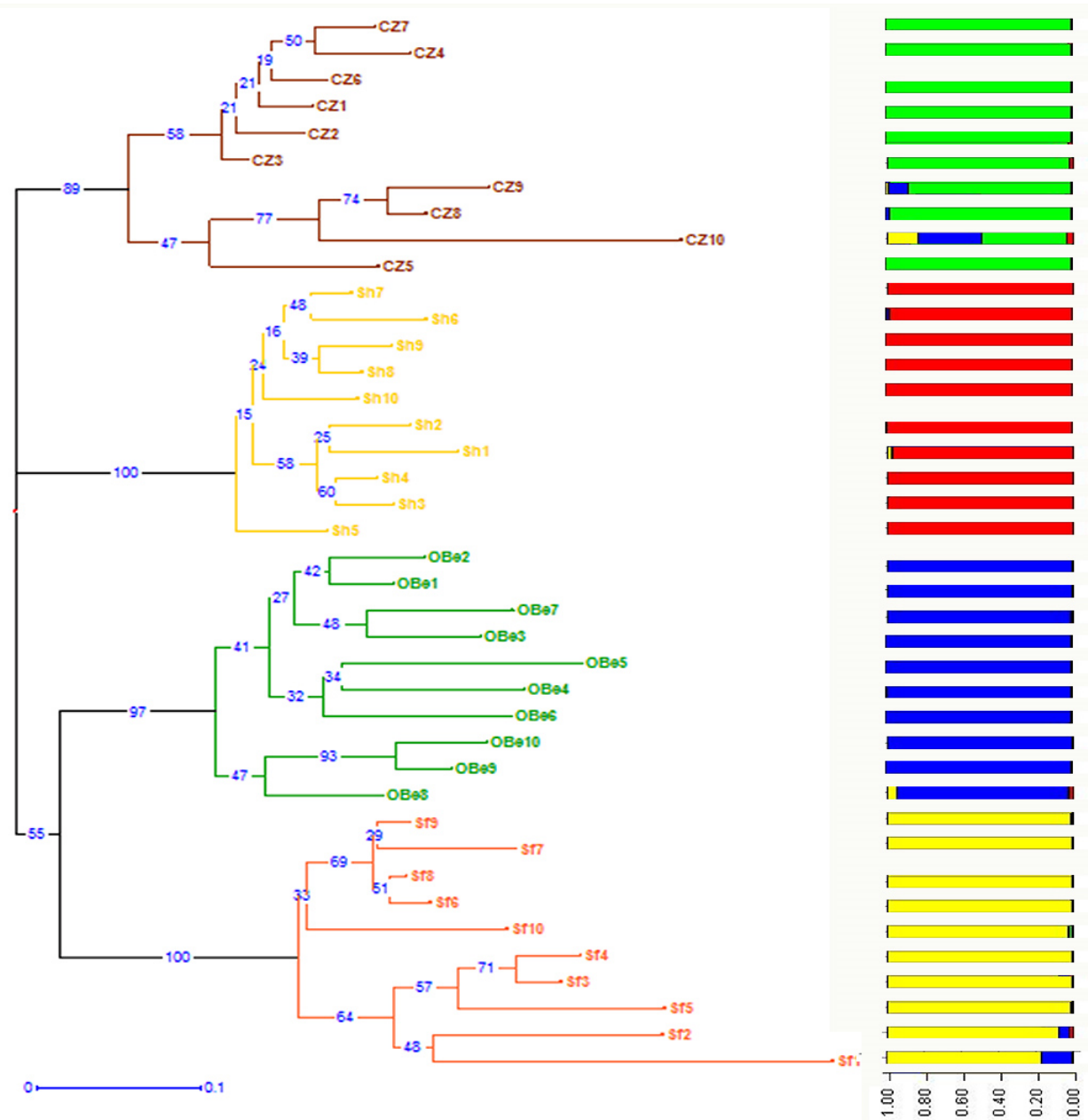

Figure 1. Dendrogram obtained using the neighbor joining (NJ) cluster analysis based on Nei's genetic distances (1973) among populations and the genetic structure assessed using STRUCTURE.

For the fine STRUCTURE model analysis, final population sub-groups were determined based on changes in the second derivative $(\Delta K)$ of the relationships between $K$ and the log likelihood (Evanno et al., 2005), and there was a clear peak in the value of $\Delta K=171.428$ at $K=4$ (Figure 2). Therefore, $\mathrm{K}=4$ best fit the data. The proportions of all individuals were assigned into four clusters, but the $\mathrm{OB}$ and $\mathrm{CZ}$ populations displayed some degree of mixed ancestry (Figure 1).

Regarding the k-means analysis, for each variation of the number of $\mathrm{K}$ clusters from $\mathrm{k}=$ 4 to $k=9$, there was an exchange of individuals between classes. Only a certain number of OB, $\mathrm{SH}$ and SS individuals per species remained stable and part of the same group independent of the $\mathrm{k}$ value. $L$. cicera individuals were continuously moving, and they had no stable group with the $\mathrm{k}[4,9]$ range. Results for $\mathrm{OB}$ and $\mathrm{SH}$ are in full agreement with those obtained with the $\mathrm{NJ}$ classification hierarchy. 


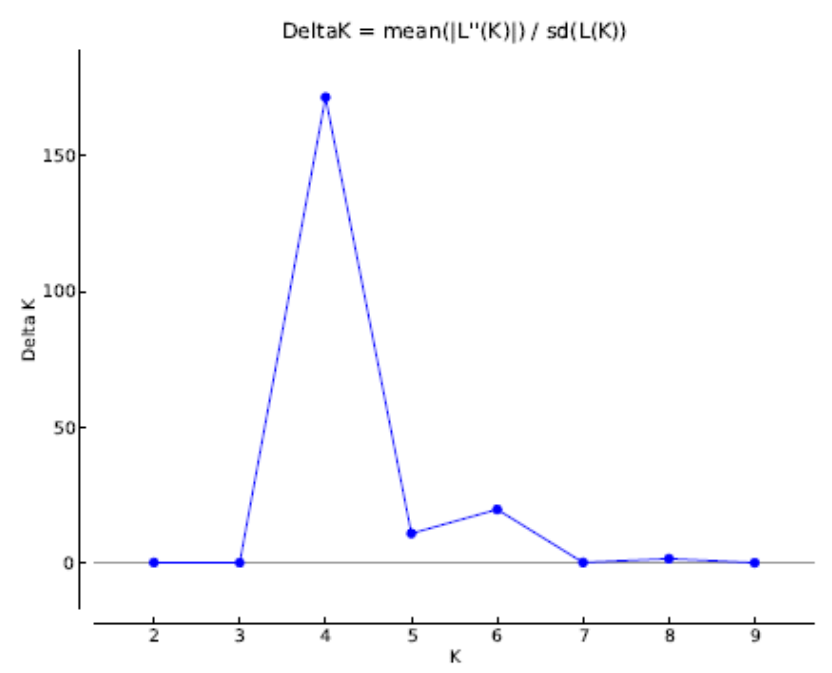

Figure 2. Results of the Bayesian assignment analysis using STRUCTURE HARVESTER.

\section{Multidimensional scaling using SRAP markers}

PCoA was performed to provide spatial representation of the relative genetic distances among individuals, and the analysis was also used to determine the consistency of differentiation among the populations defined by the cluster analysis (Figure 3). Based on the binary matrix, the resulting two main principal coordinates were mapped (Figure 4), and they explained 18.12 and $17.15 \%$ of the total variation, respectively. Regarding the PCA results, the first $\left(F_{1}\right)$ and second axes accounted for 20.61 and $18.61 \%$ of the total variance.

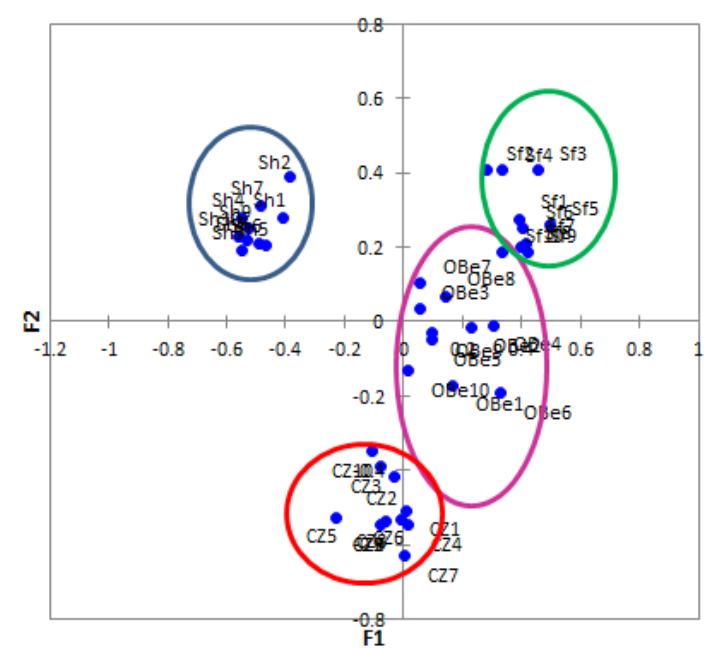

Figure 3. Principal coordinate analysis across four Lathyrus species. The variance explained by $F_{1}$ and $F_{2}$ is 18.12 and $17.15 \%$, respectively. 


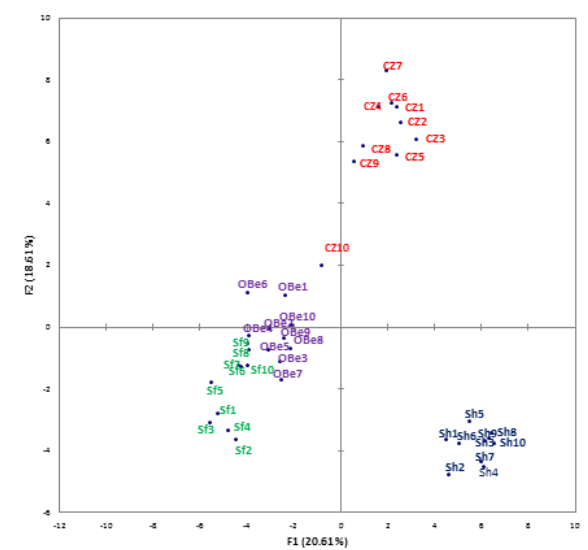

Figure 4. Principal component analysis across four Lathyrus species.

The $F_{1}$ axis (PCA and $P C o A$ ) separated the four species into two major groups. The first group includes $L$. ochrus, $L$. cicera, and $L$. sativus, and the second group includes $L$. sylvestris. This result is in agreement with that of the fine STRUCTURE model analysis results.

\section{DISCUSSION}

The SRAP marker system is becoming the marker of choice for characterization and genetic diversity studies in a wide range of plants. In our study, the SRAP markers (developed primarily for Brassica species) were used for the first time in Lathyrus. Moreover, the transferability of the markers was evaluated and used for analyses of genetic diversity and variation within and among four Lathyrus species, and they were used to estimate the species relationships. The number of polymorphisms amplified in this study was also lower than that identified in the SRAP analysis of faba beans (Alghamdi et al., 2012), which reported a total of 1036 bands using 14 primers. However, many SRAP studies congruate with the low number of alleles (Jing et al., 2013). In fact, some labeled SRAP oligonucleotides, such as FC1, BG23, and SA7, amplify more than 10 polymorphic loci, while Em2 and DC1 produce less than six (Li et al., 2013). The diversity level depends on the number and origin of the analyzed genotypes, so it is difficult to compare the levels of diversity based on the SRAP marker system results from another genus with our results. Nevertheless, most studies have confirmed the value of the SRAP method in diversity analyses of different plants.

All of the markers obtained using the SRAP marker system were subsequently used for diversity assays, and the PIC values of each primer combination were used to access their informativeness, which was determined by the number of different alleles and the corresponding frequency distribution within a population.

Diversity analyses among the Lathyrus species studied here showed the presence of moderate levels of diversity, high levels of heterozygosity, and high numbers of effective alleles observed in L. ochrus. The moderate levels of diversity observed using the SRAP marker system might be due to limited sampling, because these Lathyrus species were represented by a single population each. A moderate amount of variation was also proportioned among Lathyrus species, and it resulted in a $G_{\mathrm{ST}}$ value of 0.553 . This modest genetic diversity was also supported by the $N_{\mathrm{m}}$ value of 0.4037 , which indicated low gene flow and $58 \%$ molecular variance among Lathyrus species. 
The SRAP marker system efficiently distinguished Lathyrus species with high polymorphism levels. Reported high polymorphism levels in Lathyrus were previously based on molecular markers such as AFLP (Badr et al., 2002), ISSR (Ghorbel et al., 2014), RFLP, and RAPD (Chtourou-Ghorbel et al., 2001), and the polymorphism gradation was based on AFLP and RAPD (100\%) markers and ISSR (98.12\%) and RFLP (91.96\%) markers. Polymorphism in Lathyrus species that was based on AFLP and RAPD markers data is comparable to the SRAP-based analysis performed in this study. These results can be explained by the fact that a principal aspect of the SRAP marker system is the combination and simplification of both AFLP and RAPD protocols. Of the analyzed samples, more than $85 \%$ showed unique SRAP fingerprints, which confirmed the effectiveness of this marker for the identification of genetic diversity in Lathyrus species.

All clustering and multidimensional scaling used in this study confirmed that individuals were assigned to four principal clusters. According to the NJ dendrogram, L. ochrus and L. sativus were clustered in the same group, and this result was supported by PCA and PCoA distributions. The population genetic structure across the analyzed species identified four groups in which clustered individuals were dependent on their species, but admixture among species was also observed.

In this study, we applied the K-means method to test the contribution of analyzed individuals in the structuring of their clusters. Graphs representing the distribution of individuals relative to the barycenters showed that certain individuals, including $\left\{\mathrm{Sf}_{3}, \mathrm{Sf}_{5}, \mathrm{Sf}_{6}, \mathrm{Sf}_{7}, \mathrm{Sf}_{8}, \mathrm{Sf}_{9}\right.$, and $\left.\mathrm{Sf}_{10}\right\}$, $\left\{\mathrm{LObe}_{1}\right.$, $\mathrm{LObe}_{3}, \mathrm{LObe}_{4}, \mathrm{LObe}_{5}, \mathrm{LObe}_{6}, \mathrm{LObe}_{7}, \mathrm{LObe}_{8}, \mathrm{LObe}_{9}$, and LObe $\left.{ }_{10}\right\}$, and all L. sylvestris individuals, were always grouped together. Therefore, these groups formed the genotypes that characterized their clusters (Figure 5).

Only L. cicera individuals exhibited continuous movement associated with varied $\mathrm{K}$ values. This result can be explained and supported by the degree of mixed ancestry between some $L$. cicera individuals and other studied species. This includes the LCZ9 genotype that was genotypically similar to $L$. ochrus, and the LCZ10 genotype that was genetically similar to both $L$. ochrus and $L$. sativus.

It is interesting to compare our results with those obtained from studies of the systematic Lathyrus relationships that were conducted with molecular markers. For instance, the Lathyrus and Clymenum sections that belong the populations examined in this study were analyzed by ChtourouGhorbel et al. (2001), Ghorbel et al. (2014), and Gharbi et al. (2014) using ISSR markers, RFLP, RAPD and cpDNA trnH-psbA markers, respectively. These studies used the same populations analyzed in this study, but the results differed completely as compared to our data. All of these studies showed a close relationship between $L$. cicera and $L$. sativus, which are clustered with $L$. sylvestris in the section Lathyrus. Moreover, these studies also supported the genetic separation of L. ochrus, which was purported to belong to the section Clymenum.

The results obtained by Badr et al. (2002) (using AFLP data) and those obtained by Croft et al. (1999) (based on RAPD data) indicated that the sister relationship between $L$. sativus and $L$. cicera may be a result of hybridization and common ancestry. The results also support the classification of $L$. ochrus into the section Clymenum and the classification of L. cicera, L. sativus, and L. sylvestris into the section Lathyrus (Kupicha, 1983).

Our data are completely different, and they show an integration of $L$. ochrus into the section Lathyrus. According to our results, L. ochrus is included with $L$. sativus in the same group, so our classification does not support the monophyly of the section Lathyrus as described by Kupicha (1983).

Our data support results based on seed protein diversity that were obtained by Badr et al. (2002), which showed similarities in seed proteins between L. cicera, L. sativus, and L. ochrus. 
A
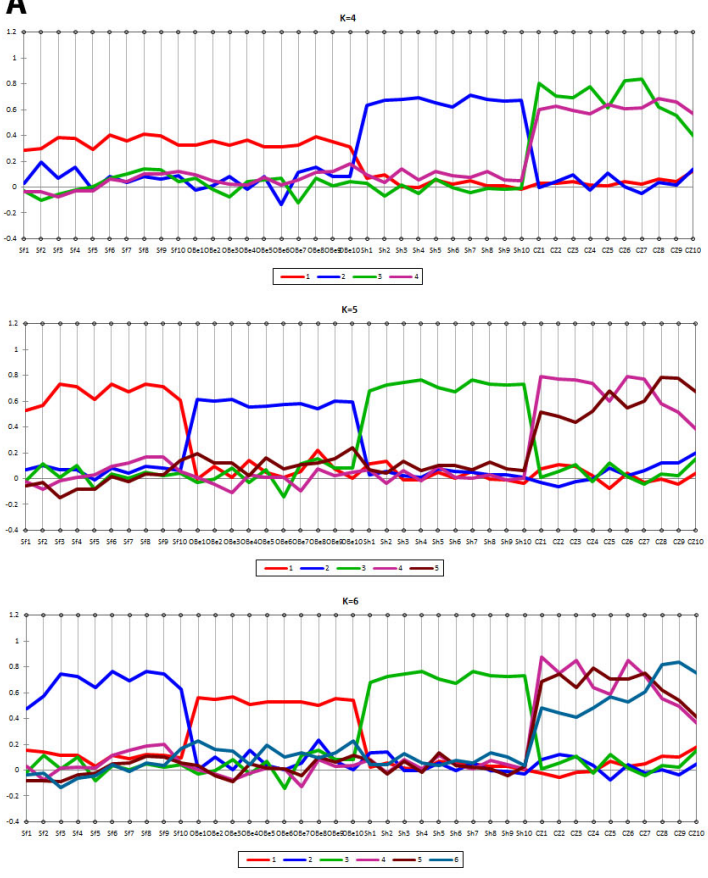

B
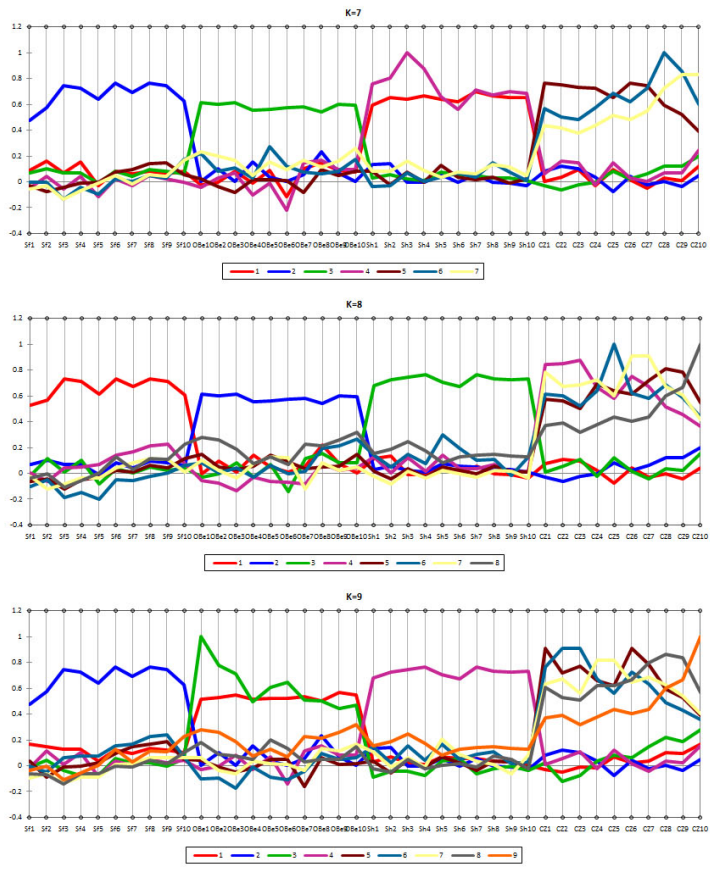

Figure 5. Individual distribution relative to barycenters with $\mathrm{K}$ value. $A . \mathrm{K}=[4-6] . \mathbf{B} . \mathrm{K}=[7-9]$. 
These results make SRAP markers choice markers for the study of functional polymorphism that is directly related to transcriptomic data. Furthermore, the results support information from Robarts and Wolfe (2014), which proposed "that use of SRAP markers should be viewed analogous to morphological character states".

In conclusion, our data initially confirmed that sets of SRAP markers provide an accurate picture of the population structure within Lathyrus germplasm, which is critically important information for the design of genetic diversity and structure analyses. Moreover, more extensive studies are necessary to fully examine other Lathyrus sections and tests that adopt the SRAP technique to enrich the Lathyrus library for next-generation sequencing, thus providing a potent protocol for the study of polymorphism.

\section{Conflicts of interest}

The authors declare no conflict of interest.

\section{ACKNOWLEDGMENTS}

Research supported by grants from the Tunisian Ministère de l'Enseignement Supérieur et de la Recherche Scientifique.

\section{REFERENCES}

Alghamdi SS, Al-Faifi SA, Migdadi HM, Khan MA, et al. (2012). Molecular diversity assessment using Sequence Related Amplified Polymorphism (SRAP) markers in Vicia faba L. Int. J. Mol. Sci. 13: 16457-16471. http://dx.doi.org/10.3390/ iims131216457

Badr A, El Shazly H, El Rabey H and Watson LE (2002). Systematic relationships in Lathyrus sect. Lathyrus (Fabaceae) based on amplified fragment length polymorphism (AFLP) data. Can. J. Bot. 80: 962-969. http://dx.doi.org/10.1139/b02-084

Belaïd Y, Chtourou-Ghorbel N, Marrakchi M and Trifi-Farah N (2006). Genetic diversity within and between populations of Lathyrus genus (Fabaceae) revealed by ISSR markers. Genet. Resour. Crop Evol. 53: 1413-1418. http://dx.doi. org/10.1007/s10722-005-5680-0

Budak H, Shearman RC, Parmaksiz I, Gaussoin RE, et al. (2004a). Molecular characterization of buffalograss germplasm using sequence-related amplified polymorphism markers. Theor. Appl. Genet. 108: 328-334. http://dx.doi.org/10.1007/ s00122-003-1428-4

Budak H, Shearman RC, Parmaksiz I and Dweikat I (2004b). Comparative analysis of seeded and vegetative biotype buffalograsses based on phylogenetic relationship using ISSRs, SSRs, RAPDs, and SRAPs. Theor. Appl. Genet. 109: 280-288. http://dx.doi.org/10.1007/s00122-004-1630-z

Chen W, Zhang Y, Liu X, Chen B, et al. (2007). Detection of QTL for six yield-related traits in oilseed rape (Brassica napus) using DH and immortalized F2 populations. Theor. Appl. Genet. 115: 849-858. http://dx.doi.org/10.1007/s00122-007$\underline{0613-2}$

Chowdhury MA and Slinkard AE (2000). Genetics of isozymes in grasspea. J. Hered. 91: 142-145. http://dx.doi.org/10.1093/ jhered/91.2.142

Chtourou-Ghorbel N, Lauga B, Combes D and Marrakchi M (2001). Comparative genetic diversity studies in the genus Lathyrus using RFLP and RAPD markers. Lathyrus Lathyrism Newsletter 2: 62-68.

Croft AM, Pang ECK and Taylor PWJ (1999). Molecular analysis of Lathyrus sativus L. (grass pea) and related Lathyrus species. Euphytica 107: 167-176. http://dx.doi.org/10.1023/A:1003520721375

Evanno G, Regnault S and Goudet J (2005). Detecting the number of clusters of individuals using the software structure: a simulation study. Mol. Ecol. 14: 2611-2620. http://dx.doi.org/10.1111/j.1365-294X.2005.02553.x

Fu FY, Liu LZ, Chai YR, Chen L, et al. (2007). Localization of QTLs for seed color using recombinant inbred lines of Brassica napus in different environments. Genome 50: 840-854. http://dx.doi.org/10.1139/G07-068

Gao M, Li G, Yang B, Qiu D, Farnham M and Quiros CF (2007). High-density Brassica oleracea linkage map: identification of useful new linkages. Theor. Appl. Genet. 115: 277-287. http://dx.doi.org/10.1007/s00122-007-0568-3 
Gharbi M, Zitouna N, Fadhlaoui I, Trifi-Farah N, et al. (2014). Molecular characterization of Lathyrus species using chloroplast DNA trnH-psbA. Biochem. Syst. Ecol. 57: 439-444. http://dx.doi.org/10.1016/j.bse.2014.09.002

Ghorbel M, Marghali S, Trifi-Farah N and Chtourou-Ghorbel N (2014). Phylogeny of Mediterranean Lathyrus species using inter simple sequence repeats markers. Acta Bot. Gallica 161: 91-98. http://dx.doi.org/10.1080/12538078.2013.878854

Gower JC (1966). Some distance properties of latent root and vector methods used in multivariate analysis. Biometrika 53: 325-338. http://dx.doi.org/10.1093/biomet/53.3-4.325

Hamrick JL and Godt MJW (1996). Effects of life history traits on genetic diversity in plant species. Philos. Trans. R. Soc. Lond. B. Biol. Sci. 351: 1291-1298. http://dx.doi.org/10.1098/rstb.1996.0112

Jing Z, Ruan X, Wang R and Yang Y (2013). Genetic diversity and relationships between and within persimmon (Diospyros L.) wild species and cultivated varieties by SRAP markers. Plant Syst. Evol. 299: 1485-1492. http://dx.doi.org/10.1007/ $\underline{\text { s00606-013-0810-1 }}$

Jones N, Ougham H, Thomas H and Pasakinskiene I (2009). Markers and mapping revisited: finding your gene. New Phytol. 183: 935-966. http://dx.doi.org/10.1111/j.1469-8137.2009.02933.x

Kupicha FK (1981). Tribe Vicieae. In: Advances in legume systematics (Polhill RM and Raven PH, eds.). Part 1. Royal Botanic Gardens Kew, Richmond, UK, 377-381.

Kupicha FK (1983). The infrageneric structure of Lathyrus. Royal Bot. Gardens 41: 209-244.

Lewis G, Schrire B, MacKinder B and Lock M (2005). Legumes of the world. Royal Botanic Gardens Kew, Richmond, UK.

Li G and Quiros CF (2001). Sequence-related amplified polymorphism (SRAP), a new marker system based on a simple PCR reaction: its application to mapping and gene tagging in Brassica. Theor. Appl. Genet. 103: 455-461. http://dx.doi. org/10.1007/s001220100570

Li G, Gao M, Yang B and Quiros CF (2003). Gene for gene alignment between the Brassica and Arabidopsis genomes by direct transcriptome mapping. Theor. Appl. Genet. 107: 168-180.

Li G, McVetty PB and Quiros CF (2013). SRAP molecular marker technology in plant science. Plant Breed. Laboratories to Fields.

MacQueen JB (1967). Some methods for classification and analysis of multivariate observations. Proceedings of 5th Berkeley Symposium on Mathematical Statistics and Probability. University of California Press, 281-297.

Nei M (1973). Analysis of gene diversity in subdivided populations. Proc. Natl. Acad. Sci. U. S. A. 70: 3321-3323. http://dx.doi. org/10.1073/pnas.70.12.3321

Peakall R and Smouse PE (2012). GenAIEx 6.5: Genetic analysis in Excel. Population genetic software for teaching and research-an update. Bioinformatics 28: 2537-2539. http://dx.doi.org/10.1093/bioinformatics/bts460

Perrier X and Jacquemoud-Collet JP (2006). DARwin software. Available at [http://darwin.cirad.fr/].

Rahman M, Sun Z, McVetty PBE and Li G (2007). Development of SRAP, SNP and SCAR molecular markers for the major seed coat color gene in Brassica rapa L. Theor. Appl. Genet. 115: 1101-1107. http://dx.doi.org/10.1007/s00122-007$\underline{0636-8}$

Riaz, A, Li G, Quresh Z, Swati MS, et al. (2001). Genetic diversity of oilseed Brassica napus inbred lines based on sequencerelated amplified polymorphism and its relation to hybrid performance. Plant Breed. 120: 411-415. http://dx.doi. org/10.1046/j.1439-0523.2001.00636.x

Robarts DW and Wolfe AD (2014). Sequence-related amplified polymorphism (SRAP) markers: A potential resource for studies in plant molecular biology. Appl. Plant Sci. 2: 1-13. http://dx.doi.org/10.3732/apps.1400017

Sarker A, Robertson LD, EI Moneim AA and Campbell CG (1997). Lathyrus species: conserved germplasm resources, priorities for collection and future prospects. Proceedings of International Food Legume Research Conference III, Adelaide, Australia.

Skiba B, Ford R and Pang EC (2004). Construction of a linkage map based on a Lathyrus sativus backcross population and preliminary investigation of QTLs associated with resistance to ascochyta blight. Theor. Appl. Genet. 109: 1726-1735. http://dx.doi.org/10.1007/s00122-004-1812-8

Smith JSC, Chin ECL, Shu H. Smith OS et al. (1997). An evaluation of the utility of SSR loci as molecular markers in maize (Zea mays L.): Comparisons with data from RFLPs and pedigree. Theor. Appl. Genet. 95: 163-173. http://dx.doi.org/10.1007/ $\underline{\mathrm{s} 001220050544}$

Sun Z, Wang Z, Tu J, Zhang J et al. (2007). An ultradense genetic recombination map for Brassica napus, consisting of 13551 SRAP markers. Theor. Appl. Genet. 114: 1305-1317. http://dx.doi.org/10.1007/s00122-006-0483-z

Vandemark GJ, Ariss JJ, Bauchan GA, Larsen RC, et al. (2006). Estimating genetic relationships among historical sources of alfalfa germplasm and selected cultivars with sequence related amplified polymorphisms. Euphytica 152: 9-16. http:// dx.doi.org/10.1007/s10681-006-9167-7

Wuletaw T, Yohannes D and Asfaw T (1997). Grass pea (Lathyrus sativus): Production and breeding in Ethiopia. In: Lathyrus and Lathyrism: A decade of Progress (Teklehaimanot R and Lambein, F, eds.). University of Ghent, Belgium, 87-90. 
Xie W, Zhang X, Huang L, Peng Y et al. (2011). Genetic maps of SSR and SRAP markers in diploid orchardgrass (Dactylis glomerata L.) using the pseudo-test cross strategy. Genome 54: 212-221. http://dx.doi.org/10.1139/G10-111

Yeh F, Yang R and Boyle T (1999). POPGENE Version 1.32. Microsoft Window-based Freeware for Population Genetic Analysis. Molecular Biology and Biotechnology Center, University of Alberta, Edmonton.

Yi Y, Liu HY, Huang XQ, An LZ, et al. (2008). Development of molecular markers linked to the wheat powdery mildew resistance gene Pm4b and marker validation for molecular breeding. Plant Breed. 127: 116-120. http://dx.doi.org/10.1111/j.14390523.2007.01443.x

Zhang J, Lu Y, Yuan Y, Zhang X, et al. (2009a). Map-based cloning and characterization of a gene controlling hairiness and seed coat color traits in Brassica rapa. Plant Mol. Biol. 69: 533-563. http://dx.doi.org/10.1007/s11103-008-9437-y

Zhang ZS, Hu MC, Zhang J, Liu D, et al. (2009b). Construction of a comprehensive PCR-based marker linkage map and QTL mapping for fiber quality traits in upland cotton (Gossypium hirsutum L.) Mol. Breed. 24: 49-61. http://dx.doi.org/10.1007/ s11032-009-9271-1 